\title{
Convergência da tecnologia e a intenção de consumo no setor automobilístico: uma pesquisa netnográfica
}

\author{
Emilio José Montero Arruda Filho e Luis Augusto Molina Alexandroni
}

\section{RESUMO}

O cenário da convergência tecnológica representado pela conexão do celular do usuário ao sistema de som, a disponibilidade no painel do carro de um GPS e a câmara de auxílio para as manobras traz uma percepção de multifuncionalidade para o processo de decisão de compra dos novos automóveis. Compreender se os fatores tecnológicos influenciam a intenção de consumo no mercado automobilístico brasileiro, quando mediados pelos valores percebidos do produto, foi o objetivo da presente pesquisa. O método de pesquisa foi qualitativo (netnografia) com o auxílio de uma ferramenta de Big Data. Fez-se um levantamento desses fatores motivacionais e observou-se que nas intenções de consumo estão presentes os valores hedônicos, utilitários e sociais, por meio de características como prazer em dirigir, apreciação por tecnologia, economia, racionalidade na decisão de compra, extensão da personalidade e afirmação da personalidade perante o grupo social. Constatou-se também a ocorrência da devoção ao produto e/ou fabricante representada por características como paixão, sonho de consumo e valorização dos diferenciais do automóvel. Os dados analisados foram os comentários postados no Facebook da Fiat, Ford e Volkswagen. Observou-se também a presença de categorias negativas relacionadas à motivação para o consumo como o medo para consumir e a expectativa frustrada após a compra.

Palavras-Chave: convergência tecnológica; big data; valores hedônicos; valores utilitários; valores sociais.

\section{Technology convergence and the consumption intention in the automotive sector: a netnographic research}

\section{ABSTRACT}

The technological convergence scenario represented by the connection of the user's cell phone to the sound system, the availability of a GPS and maneuvering camera on the dashboard car brings a perception of multifunctionality to the decision process of buying new cars. The objective of this research was to understand whether technological factors influence consumption intent in the Brazilian automobile market, when mediated by the perceived values of the product. The research method was qualitative (netnography) with the aid of a tool of Big Data. It was made a survey of these motivational factors and it was observed that in the intentions of consumption the ones that are present are the hedonic, utilitarian and social values, through characteristics like pleasure in driving, appreciation by technology, economy, rationality in the purchase decision, extension of personality (extended self) and affirmation of personality towards the social group. It was also verified the devotion to the product and/or manufacturer represented by characteristics such as passion, dream of consumption and appreciation of the differentials of the automobile. The data analyzed were the comments posted on Facebook from Fiat, Ford and Volkswagen. It was also observed the presence of negative categories related to the motivation for the consumption as the fear to consume and the frustrated expectation after the purchase.

Keywords: technological convergence; big data; hedonic values; utilitarian values; social values.
Recebido em: 23/03/2020 Revisado em: 15/09/2020 Aprovado em: 16/11/2020

Check for updates

\section{Emilio José Montero Arruda Filho (iD,}

Universidade da Amazônia, Brasil Doutor em Marketing, Università Degli Studi Di Bergamo, Itália

emilio.arruda@unama.br

Luis Augusto Molina Alexandroni iD,

Universidade FUMEC, Brasil Mestre em Administração de Empresas, Universidade FUMEC, Brasil

lalexandroni@gmail.com 
Introdução

O setor automotivo representa aproximadamente $23 \%$ do PIB industrial e ele é importante na medida em que seu desempenho afeta significativamente a produção de diversos outros setores industriais, como o de aços e derivados, máquinas e equipamentos, materiais eletrônicos, produtos de metal e artigos de plásticos e borracha, conforme o Ministério do Desenvolvimento, Indústria e Comércio Exterior [MDIC] (2016) aponta.

A grande variedade de marcas, modelos, tamanhos e estilos de automóveis atualmente existentes no mercado, bem como o fato desse produto ser um bem durável de custo elevado, implica numa compra de alto envolvimento. Isto requer uma prolongada reflexão e pesquisa de informação em relação às características utilitárias. O custo envolvido traz um risco associado, tornando a decisão de compra do setor automobilístico complexo com diversas variáveis envolvidas (Satish \& Bharadhwaj, 2010; Sahin, Zehir, \& Kitapçi, 2011; Nayeem \& Casidy, 2015; Blackwell, Miniard, \& Engel, 2008; Shamdasani, Stanaland, \& Tan, 2000; Mowen \& Minor, 2002; Pereira, 2016).

Itens como capacidade de passageiros, espaço no porta-malas, consumo de combustível e itens de segurança, são funcionalidades representantes do valor utilitário que, aliados à categoria de um carro luxuoso, nos quais os recursos de entretenimento e o design arrojado, estimuladores do prazer de dirigir e de possuir representam o valor hedônico, temos, então, os elementos levados em consideração na decisão pela compra de um automóvel (Okada, 2005; Batra \& Ahtola, 1990; Hirschman \& Halbrook, 1982; Mano \& Oliver, 1993, Sela \& Berger, 2012; Dhar \& Wertenbroch, 2000; Meyer \& Sathi, 1985).

Aos dois valores descritos (utilitários e hedônicos), descreve-se também o valor social decorrente da confrontação entre a própria personalidade (self) e o grupo social em que o consumidor está inserido. Essa confrontação gera no consumidor a atração pelo modismo, que é a necessidade emocional das pessoas em se manterem a par das mudanças produzidas pela moda e, assim, manterem a sua identidade social (Katz \& Sugiyama, 2006). Assim, tem-se os três valores, hedônico, utilitário e social, impactando de forma conjunta, na intenção de consumo do produto automóvel.

Logo, compreender se o contexto da convergência tecnológica modifica o processo de consumo, aumentando a percepção de valor com o produto e assim aumentando a intenção de consumo, é o objetivo central do presente estudo, identificando a tecnologia convergente no automóvel como um atributo que tende a fazer com que a intenção de consumo seja condicionada, ora por valores mais racionais, ora por valores mais prazerosos. Assim, é necessário compreender: como a convergência da tecnologia nos automóveis pode aumentar a percepção de atributos e benefícios aos consumidores, aumentando assim seu interesse de consumo?

Para o levantamento dos dados foi então escolhida a netnografia ou etnografia online, que segundo Kozinets (2014), pode ser definida como uma forma especializada de etnografia adaptada às contingências específicas dos mundos sociais de hoje mediados pelos computadores. O Buzzmonitori, 
uma ferramenta baseada no Big Data, foi útil para otimizar o processo de acompanhamento e coleta dos dados. Após análise do conteúdo contido nas discussões postadas no Facebook das três montadoras selecionadas, foi possível conhecer e classificar as categorias associadas aos perfis dos consumidores de automóveis no âmbito nacional.

\section{A intenção de consumo automobilístico e os valores motivacionais}

A afirmação de que o consumo é, antes de tudo, um ato simbólico e coletivo, promoveu um grande deslocamento nos modos dominantes de pensar esse fenômeno no universo de pesquisas em Marketing, especialmente a partir dos anos 1980 até os dias atuais, em que essa forma de entender o consumo vem se aprimorando (Rocha \& Barros, 2006).

De acordo com estes mesmos autores, além de outros (Mauss, 1974; Sahlins, 1979; Campbell, 1987; Douglas \& Isherwood, 1978), nem o dinheiro, nem a razão prática e nem a lógica econômica explicam os diferentes significados do consumo.

O consumo apenas se reduz a um fato econômico, algo capaz de igualar todos pela via da posse do dinheiro, até a fronteira do preço de entrada, pois a partir daí, são diferenças de uma ordem mais complexa que passam a governar.

Se, por um lado o consumo pode ser visto como uma forma de extensão da própria personalidade (Belk, 1988), por outro, o consumo pode ser visto como um fato social capaz de gerar representações coletivas (Durkheim, 1968). O consumo, inversamente, é sensível às interpretações que envolvem significados culturais e públicos (Rocha \& Barros, 2006), podendo até mesmo ocorrer situações em que as ligações dos consumidores com marcas atingem um nível de lealdade tão intenso, que tal lealdade sobrevive ao fraco desempenho do produto, ao escândalo, à má publicidade, aos elevados preços e à ausência de esforços promocionais (Pimentel \& Reynolds, 2004).

Veludo-de-Oliveira e Ikeda (2005) ressaltam que o valor confronta percepções e escolhas, não estando vinculado somente ao aspecto econômico que tange a compra de um produto.

De acordo com Woodruff (1997, p.140), valor pode ser considerado sob a perspectiva da organização e do cliente (customer value), e é essa última a perspectiva da presente pesquisa. Para Schechter (1984 como citado em Zeithaml 1988, p. 13) "valor para o cliente são todos os fatores, qualitativos e quantitativos, subjetivos e objetivos, que compõe a experiência completa de compra".

A partir dos elementos apresentados nesta seção, pode-se entender bens hedônicos (relacionados aos valores hedônicos) como aqueles cujo consumo é caracterizado principalmente por uma experiência afetiva e sensorial de prazer estético ou sensual, fantasia e diversão, enquanto que os bens utilitários (relacionados aos valores utilitários) como aqueles cujo consumo é mais cognitivamente dirigido, instrumental e orientado para o objetivo, de forma a realizar uma tarefa funcional ou prática (Hirschman \& 
年, Khan \& Dhar, 2010).

Valor hedônico pode ainda surgir do próprio prazer do consumidor e do seu gosto, bem como da experiência de consumo com o produto (Perrea, Grunert, \& Krystallis, 2015), como citado em (Papista, E., Chrysochou, Krystallis, \& Dimitriadis, 2018).

As alternativas hedônicas são mais afetivas e experimentalmente atraentes do que as alternativas utilitárias. Tanto os bens hedônicos como os utilitários oferecem benefícios ao consumidor, o primeiro especialmente sob a forma de prazer e satisfação e o último em termos de funcionalidade prática (Okada, 2005; Batra \& Ahtola, 1990; Hirschman \& Holbrook, 1982; Mano \& Oliver, 1993).

Uma alternativa hedônica tende a ser avaliada de forma mais elevada do que uma alternativa utilitarista quando estas são apresentadas isoladamente, mas a alternativa utilitarista tende a ser escolhida sobre a alternativa hedônica quando as duas são apresentadas em conjunto. São diferentes também os dispêndios de tempo e dinheiro gastos nos itens hedônicos e utilitários (Okada, 2005; Ozcan \& Sheinin, 2015).

\section{A convergência tecnológica e a instrumentação adequada para compreensão}

\section{O automóvel e a convergência tecnológica}

Luiz Carlos Moraes, atual presidente da Associação Nacional dos Fabricantes de Veículos Automotores (ANFAVEA), uma associação de 26 marcas que produzem mais de 2.000 modelos e versões de veículos no Brasil, em 65 fábricas, com presença em 43 cidades de 10 estados da federação, esclarece que o modelo de negócio de toda a cadeia automotiva está em rápida e profunda transformação. A automação avança em ritmo acelerado, bem como a conectividade entre veículos e até entre cidades e estradas "inteligentes" Associação Nacional dos Fabricantes de Veículos Automotores (ANFAVEA, 2020).

Neste cenário, a convergência é caracterizada pela superposição e incorporação de aplicações, anteriormente separadas nas diversas indústrias (Kim, Lee, \& Koh, 2005). É o caso dos smartphones, no qual funcionalidades como telefone celular, máquina fotográfica e aparelho de som são unificados num único aparelho.

Um exemplo de utilização dos recursos tecnológicos no automóvel é o do chamado iCARII. Trata-se de um esquema de roteamento baseado em infraestrutura para aplicações de recursos de informática aplicados ao entretenimento veicular somado ao acesso à Internet no cenário da mobilidade urbana (Alsharif \& Shen, 2014; Frese, Gerber, Hatebur, Côté, \& Heisel, 2018).

Os automóveis atuais possuem sistemas de multimídia que convergem tecnologias dos sistemas móveis do usuário com o automóvel em questão, 
além de inserir relações de GPS, televisão, sistemas de segurança e interação com os indivíduos dentro do veículo. Qualquer inserção de novas tecnologias fora do processo convencional automobilístico existente anteriormente é descrita como convergência tecnológica, atraindo desde relações de internet, telefonia e redes sociais, como questões de qualidade do automóvel por sensores de temperatura, qualidade dos pneus e outros, tudo digitalmente integrado ao sistema de controle automotivo e carroceria do carro.

Transformar um carro comum em smart (carro inteligente) já é possível no Brasil. Com serviços de Google, Apple e Amazon, é possível realizar chamadas, trocar de músicas ou até mesmo solicitar rotas no GPS apenas por meio de comandos de voz, a exemplo de caixas de som inteligentes (Toledo, 2020).

Num artigo publicado numa revista brasileira tradicional do setor automobilístico sobre dois modelos de automóveis da Fiat, temos a descrição da convergência tecnológica automotiva:

A grande novidade implementada nos modelos é o sistema multimídia Uconnect, já muito comum em diversos veículos da Fiat Chrysler Automobiles (FCA), e há muito tempo cobrada para o sedã e para o hatch. O dispositivo vem como item de série no Linea e na versão T-Jet do Punto, com tela sensível ao toque de cinco polegadas, reprodução de músicas por áudio streaming, conexão Bluetooth, entrada USB, sistema leitor e de envio de mensagens de texto e comando de voz (Furlan, 2015).

O automóvel, em boa parte como resultado da evolução tecnológica sofrida por essa indústria, tornou-se um produto composto por múltiplas categorias. Isso faz com que as decisões de compra dos usuários se voltem para posições hedônicas (Heath \& Soll, 1996), gerando assim, o valor hedônico, aquele que proporciona prazer e satisfação (Okada, 2005; Lee, Lee, \& Garrett, 2013), e que pode se sobrepor ao valor utilitário, mais relacionado com as funcionalidades do produto (Sheth, Mittal, \& Newman, 2001).

A convergência da tecnologia são serviços diferenciados em um mesmo produto, como o fato de se entrar no carro e atender o telefone enquanto dirige, além de se ter direcionamento pelo GPS para o local de movimentação, paralelamente calculando se o combustível será o necessário, ou quando se deverá fazer uma parada. A ideia é transpor desde relações de compartilhamento de rota, à conectividade digital, câmeras no automóvel e sensores internos e externos para diversas aplicações que podem ser tanto vislumbradas como associadas a valores utilitários, como hedônicos ou sociais (Lee et al., 2003; Li, Liu, \& Luk, 2017).

Desta forma, tem-se os valores utilitários e os valores hedônicos no contexto da convergência tecnológica se inter-relacionando com o valor social e todos esses fatores relacionados ao contexto emocional, influenciando a intenção de consumo de automóveis.

Na Figura 1, é apresentado um diagrama que descreve o foco da presente pesquisa, no qual consta a interconexão dos valores e suas relações com a intenção de consumo. 

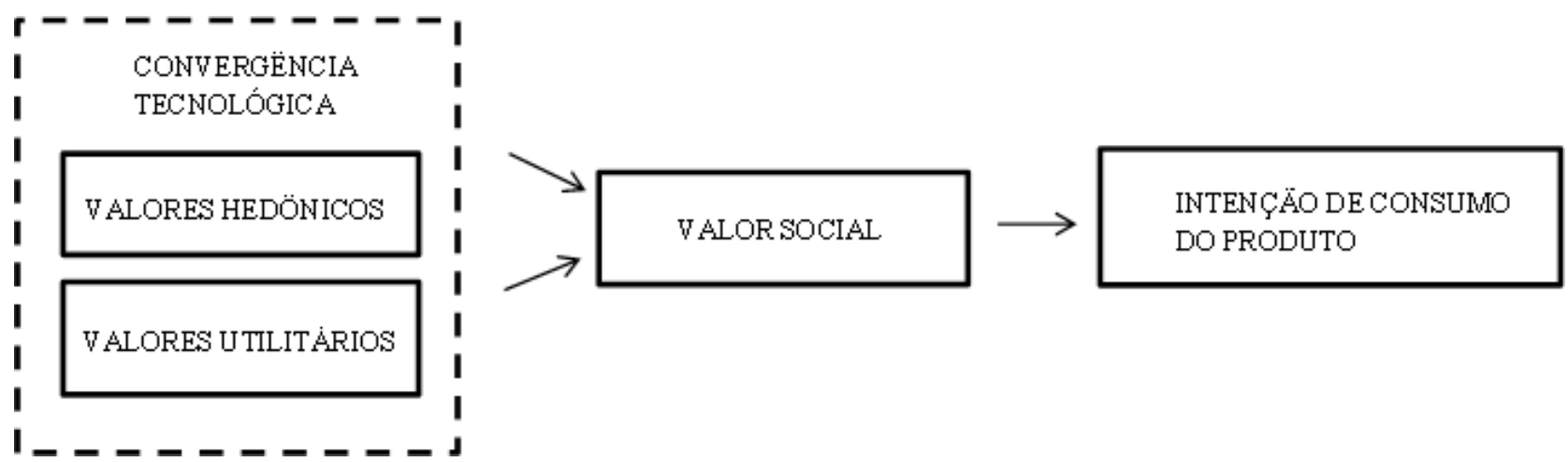

Figura 1: Esquema descritivo da pesquisa

Fonte: Adaptado de Arruda-Filho \& Dholakia (2013)

\section{Big Data e rede social como instrumento de estudo para o setor automobilístico}

As tecnologias que estão se incorporando ao dia a dia, às vezes não perceptíveis (como a computação em nuvem, Big Data, realidade mista e aumentada, a Web Semântica, a mobilidade contínua, a computação ubíqua e os dispositivos móveis multifuncionais chegando às mãos de mais pessoas), apontam mudanças e transformações nas atividades pessoais e nas relações interpessoais (Medeiros Neto, 2016).

Dentre os diversos instrumentos tecnológicos disponíveis na sociedade atual, para a fase de coleta de dados desta pesquisa, utilizou-se a tecnologia Big Data, por meio de uma ferramenta de mercado, o Buzzmonitor. Quanto ao ambiente de aplicação da netnografia, o meio de utilização foi a rede social Facebook de três montadoras de automóveis, conforme descrito no tópico Metodologia apresentado mais adiante. Cabe, portanto, uma breve descrição do conceito do Big Data e a existência das comunidades online presentes nas redes sociais.

Segundo Hofacker, Malthouse, \& Sultan (2016), o comportamento do consumidor nas mídias sociais representa um grande fator do fenômeno Big Data. O crescimento exponencial resultante no uso das mídias sociais pelo consumidor e o crescimento da Internet das Coisas manifesta os 3 Vs: Volume, Velocidade e Variedade, parte das dimensões do Big Data. Daí a importância de se entender melhor a potencialidade da utilização desse fenômeno no que tange ao comportamento do consumidor.

Hofacker et al. (2016), citando o resultado de uma pesquisa realizada pela "EMarketeri", relata que, nesse estudo de 2013 com foco nos comerciantes seniores nos EUA, 85\% dos executivos de agências e responsáveis por marcas disseram que o Big Data propiciou mais da metade das iniciativas de marketing quando se tratava de aumentar as percepções sobre o comportamento do consumidor pelo uso das redes sociais.

A internet das coisas interage na conectividade digital que o usuário possui com todas as ferramentas tecnológicas deste, organizando horários, agenda, tempo de partida para sair de casa, entre outros, que quando associado a sistemas multimídia dos automóveis, se integram às informações 
que estes dispõem para facilitar interações sociais, de conectividade e temporalidade junto aos dados das redes sociais, além da quantidade de informações que podem ser capturadas quando compartilhadas pelas redes sociais dos indivíduos.

A convergência de tecnologia, incluindo a Inteligência Artificial (IA), Internet das Coisas (IOT) e a quinta geração de comunicação de dados (5G), está inaugurando uma era de conectividade inteligente e está tornando possíveis produtos e serviços que há alguns anos atrás eram inconcebíveis. Além disso, está promovendo novas e estimulantes parcerias dentro e entre os setores. Por exemplo, os fabricantes de automóveis estão fazendo parceria com grandes tecnologias para integrar tecnologia de voz com empresas de mídia e, assim, fornecer serviços de streaming (Petrock, 2020).

Ao descrever o Big Data, é importante compreender a utilidade das redes sociais numa pesquisa na área mercadológica, uma vez que essas redes são um de seus componentes. Mayfield (2008, como citado em Ferreira, 2015) descreve cinco principais características das novas mídias sociais: (1) participação, que significa incentivar as pessoas a contribuir livremente, para criar e compartilhar conteúdos próprios; (2) abertura, na medida em que propicia à maioria uma abertura à participação, encorajando os indivíduos a aderir, selecionar, usar e compartilhar conteúdos, facilitando o acesso rápido e simples; (3) conversação, que mais do que transferir as informações de uma forma massiva, como as mídias tradicionais, configura-se em uma comunicação de muitos para muitas partes; (4) comunidade, ao permitir aos usuários compartilharem os mesmos interesses em uma ou mais plataformas virtuais e (5) conectividade, pois há sempre um atalho para outros conteúdos, ou outras redes comunicativas, sendo possível ter uma página de perfil virtual alcançando outros indivíduos, plataformas, aplicações e conteúdos.

Um instrumento de organização de Big Data pode ser descrito como uma ferramenta de organização de conjunto de dados, cujo tamanho supera a capacidade do banco de dados típico e das ferramentas de software utilizadas para capturar, armazenar, gerenciar e analisar conteúdos e informações, além de trazer a contribuição de diversificação da informação em amplitude e longitude (Maniyka et al., 2011).

Esses mesmos autores afirmam que a definição do conceito de Big Data é intencionalmente subjetiva e incorpora uma definição variável no sentido de que não se define Big Data em termos de tamanho, tal como certo número de terabytes (milhares de gigabytes).

É também possível entender o Big Data, à luz dos autores MayerSchönberger e Cukier (2013) como a capacidade de uma sociedade em obter informações de maneiras novas a fim de gerar ideias úteis e bens e serviços de valor significativo. Como as redes sociais e as discussões da atualidade geram uma quantidade considerável de ideias, conteúdos e informações, a simples coleta de dados tradicionais para análise para a netnografia traria como resultado as primeiras fontes encontradas no desenvolvimento do estudo, diferente do uso atual aqui representado, o qual usando de um instrumento de Big Data, pode organizar as palavras chaves para compreender quais discussões seriam mais relevantes para serem interpretadas por seus conteúdos e contextos envolvidos. 
Um dos meios utilizados pelas empresas no sentido de promover seus produtos vem sendo cada vez mais as redes sociais. Novas formas de comunicação, baseadas na internet, podem ter um impacto relevante na propagação de um produto por meio do marketing boca a boca.

A decisão de compra por parte do consumidor familiarizado com a internet recebe influência das chamadas comunidades virtuais ou comunidades online. Logo, esse ambiente propicia contextos em que os consumidores muitas vezes participam de discussões cujos objetivos incluem tentativas para informar e influenciar consumidores sobre produtos e marcas, e que possuem consigo algum grau de relacionamento (Goldenberg \& Muller, 2001; Kimura, Basso, \& Martin, 2008) ; Kozinets, 1999; Muniz \& O’Guinn, 2001).

Ao disponibilizarem as informações num grande volume e em tempo real, tornando as informações nelas contidas um acervo útil para as empresas observarem e melhor compreenderem a manifestação dos valores que influenciam as intenções de consumo de seus produtos, as redes sociais inseridas no contexto do Big Data tornam-se um valioso instrumento para o embasamento da presente pesquisa.

A ferramenta de Big Data Buzzmonitor, utilizada para acompanhamento e coleta dos dados, é definida por Beleza (2013) como uma plataforma de Business Intelligence e Relacionamento nas Redes Sociais, possibilitando, numa única plataforma, monitorizar tudo o que se diz espontaneamente sobre as marcas e seus concorrentes.

\section{Metodologia}

Günther (2006) afirma que a pesquisa qualitativa deve ser utilizada para estudar um fenômeno no seu contexto natural, sem que o pesquisador tenha controle das variáveis presentes no caso estudado, e foi esse o procedimento escolhido por se mostrar o mais adequado para esta pesquisa. Já a forma empregada para a análise dos dados foi tipicamente indutiva, construída a partir das peculiaridades percebidas para os temas gerais e em função das interpretações feitas pelo pesquisador sobre o significado dos dados.

O método qualitativo utilizado na pesquisa foi a netnografia (Kozinets, 2002), por meio da qual houve uma observação passiva (Langer \& Beckman, 2005) do comportamento de membros atuantes no Facebook de três fabricantes da indústria automobilística, a saber, FIAT, FORD e VOLKSWAGEN. Essas empresas foram selecionadas segundo três critérios: antiguidade da empresa no território nacional, participação de mercado em termos de automóveis licenciados, que correspondeu em 2015 a 36,5\% conforme a ANFAVEA (2016) e volume de postagens em suas páginas do Facebook. A utilização da netnografia não participante ou passiva permitiu a captura do fluxo espontâneo e disponível de comunicação entre os consumidores de forma rápida e com dados anteriores ao período que se conecta à rede (Arruda-Filho \& Lennon, 2011; Belk \& Kozinets, 2017; Sharma, Ahuja, \& Alavi, 2018).

A netnografia passiva possibilita a coleta de dados no espaço temporal amplo, podendo se buscar informações de períodos anteriores ao momento 
da pesquisa, além de apenas coletar (observar) informações sem deixar os participantes das redes sociais constrangidos em função da participação de discussões que sejam de conhecimento destes, as quais serão analisadas por pesquisadores posteriormente, o que pode causar certo desconforto no processo participativo (Arruda Filho, 2020). Todo esse processo é desenvolvido mantendo claramente a privacidade dos autores e demais dados confidenciais.

Como rede social analisada, optou-se pelo Facebook por ser aquela que reúne simultaneamente a participação dos fabricantes e dos consumidores de automóveis, além da quantidade expressiva de informações nela disponibilizadas, possibilitando assim um extenso material de pesquisa (Mayer-Schönberger \& Cukier, 2013, p. 5). Criada por Mark Zuckerberg e outros estudantes da Universidade de Harvard no ano de 2004, o Facebook é um dos sites de rede social com o maior crescimento entre redes semelhantes, possuindo milhões de usuários em diversos países (Prado, Lucas, \& Herrero-Curiel, 2013, p.5).

Kozinets (2002) ressalta que, quando os laços são fortes, unindo consumidores pertencentes a um grupo online, dado a afinidade e experiência cotidiana de participação destes membros, que neste caso foi a comunidade formada pelos usuários do Facebook, a comunicação no grupo é profundamente reveladora de suas posições, preferências, opiniões etc. Desta forma, a espontaneidade das discussões permite uma análise livre de viés (Kozinets, Scaraboto, \& Parmentier, 2018).

Neste ambiente, a netnografia evidencia as percepções culturais de um grupo específico de usuários por meio de comentários postados em sites e blogs. Possui a vantagem de ser mais rápida, mais simples, mais econômica que a etnografia tradicional e mais discreta que os grupos focais e as entrevistas (Smith \& Smith, 2018).

Como técnica de pesquisa de marketing, usou-se a netnografia para a coleta da informação que estava disponível ao público nos fóruns online com o intuito de identificar e compreender as necessidades e influências na tomada de decisão dos grupos de consumidores relevantes para este estudo nesse ambiente virtual de análise (Kozinets, 2002; Kozinets et al., 2018; Arruda Filho, 2020).

Conforme observado por Kozinets et al. (2018), abre-se para o pesquisador de marketing como que uma janela para os comportamentos que ocorrem de forma natural entre os consumidores. Trata-se de uma combinação única, não encontrada em qualquer outro método de pesquisa de marketing.

A natureza eletrônica dos dados facilita a coleta na pesquisa netnográfica, surgindo, assim, registros em forma de diálogo e também comentários entre os participantes da comunidade virtual, dispensando transcrições. Essa facilidade na aquisição de dados possibilita a interação com um expressivo volume de informações e grande busca por comunidades com contribuições e conteúdos relevantes ao estudo proposto (Kozinets, 2002; 2014). 
A netnografia possui cinco fases que estão descritas na Figura 2.

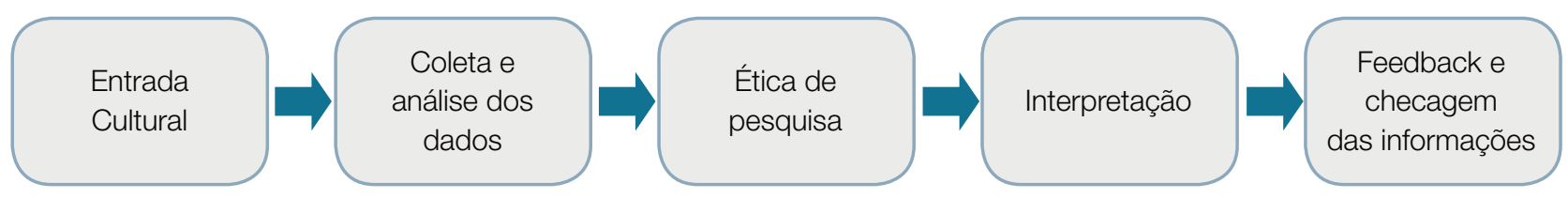

Figura 2. Fases da netnografia

Fonte: Adaptado de Ferreira (2015) e Kozinets (2014)

Das cinco fases da netnografia apresentadas anteriormente, somente as quatro primeiras foram utilizadas na presente pesquisa. Cabe destacar a fase da coleta dos dados que contou com o auxílio do Buzzmonitor, que como descrito no site da sua fornecedora, é uma suíte de soluções de software, acompanhada de uma consultoria para gestão interna de estratégias em mídia social. Produzida pelo grupo empresarial E.life, a ferramenta está baseada no Big Data. Assim, foi possível acompanhar em tempo real tudo o que foi postado sobre as marcas observadas. Tal ferramenta possibilitou uma coleta dos dados mais rápida, isto é, das discussões dos participantes do Facebook da Fiat, Ford e Volkswagen, graças à sua funcionalidade de filtragem.

O período de coleta iniciou-se no dia 14/03/2019 e terminou em 14/04/2019. Essa coleta foi publicada no Relatório Buzzmonitor contendo um total de 4.138 páginas (formato pdf). As mesmas foram apresentadas em forma de relatório dinâmico no próprio site do Buzzmonitor, uma vez que esse software foi utilizado na modalidade remota, ou seja, acessado no servidor dentro da empresa responsável pela ferramenta.

Uma vez coletadas as discussões a serem analisadas, os dados principais foram copiados no aplicativo Word, em 2/3 do lado direito de cada uma das 36 páginas que totalizaram a coleta. As 4.138 páginas baixadas pelo Buzzmonitor foram filtradas, organizadas e identificadas as discussões sobre o argumento específico da pesquisa, de modo a avaliar as características que influenciaram no processo de decisão. Após um processo detalhado de reorganização dos dados para garantir os conteúdos específicos de análise para o estudo utilizando das ferramentas próprias do Buzzmonitor, o documento final com 36 páginas no Word foi gerado. No espaço restante de 1/3 de cada página do documento Word utilizado para análise, após serem copiados os conteúdos determinados, foram feitas as observações pelo pesquisador, nas quais, mais especificamente, foram realizadas as codificações e depois identificadas as categorias dos consumidores analisados. A análise foi desenvolvida manualmente utilizando-se de leitura, marcação do texto, identificação de frases e palavras com significados relacionados, codificações específicas e categorizações (Smith \& Smith, 2018).

Os dados, após analisados, foram copiados para uma tabela criada no Word ( $2^{\circ}$ documento desenvolvido). Essa tabela conteve três colunas, totalizando 7 páginas tamanho A4 (redução das 36 páginas inicial de análise para 7 páginas com os resultados). Na primeira coluna dessa tabela foram inseridas as categorias temáticas tal como identificadas no memorando de coleta. Na segunda coluna identificou-se a página e linha correspondente dos 
comentários coletados e contidos no memorando de coleta e, finalmente, na terceira coluna, inseriu-se as frases transcritas e também contidas no memorando de coleta.

Para o tratamento dos dados foi utilizada a técnica de análise de conteúdo proposta por Bardin (1979, p.42) que a define como "um conjunto de técnicas de análise das comunicações, visando alcançar por procedimentos sistemáticos e objetivos de descrição do conteúdo das mensagens, indicadores que permitam a inferência de conhecimentos relativos às condições de produção e recebimento dessas mensagens".

$\mathrm{Na}$ Tabela 1 encontram-se os sites dos quais foram extraídas as discussões e mais alguns detalhes referentes à fonte de dados utilizada na presente pesquisa.

Tabela 1: Dados extraídos da internet para análise de comentários dos usuários de automóveis das marcas Fiat, Ford e Volkswagen

\begin{tabular}{ll}
\hline \multicolumn{1}{c}{ Redes sociais pesquisadas } & \multicolumn{1}{c}{$\begin{array}{c}\text { Endereços Eletrônicos dos sites utilizados na } \\
\text { coleta dos dados (URL's) }\end{array}$} \\
\hline Facebook da Fiat Automóveis Brasil & https://www.facebook.com/fiatbr/ \\
Facebook da Ford Brasil & https://www.facebook.com/FordBrasil/ \\
Facebook da Volkswagen do Brasil & https://www.facebook.com/volkswagendobrasil/ \\
Período da coleta dos dados & De 14 de março de 2019 até 14 de abril de 2019 \\
Total de Páginas do Banco Netnográfico & 36 páginas \\
Total de Discussões Extraídas & 486 \\
Idioma das Discussões & Português \\
Ferramenta utilizada na coleta & Buzzmonitor $\left(^{*}\right)$ \\
\hline
\end{tabular}

${ }^{*}{ }^{*}$ marca registrada do Grupo E.Life

Fonte: Elaborado pelo autor (2019).

\section{Resultados}

Uma vez concluída a pesquisa netnográfica, os dados coletados e confrontados com os conceitos teóricos foram organizados em categorias, sendo estes aspectos conclusivos em uma pesquisa qualitativa. Tal processo teve a pretensão de auxiliar na compreensão da problemática da presente pesquisa, visando o alcance do seu objetivo: compreender, no contexto da convergência tecnológica, se a inclusão de serviços multifuncionais motiva o consumo automobilístico brasileiro em função dos valores percebidos pelos indivíduos.

Foram encontradas seis categorias, conforme descritas no Quadro 1. Quatro delas são categorias mais associadas a uma visão positiva do consumidor com relação ao fabricante e ao produto, e duas decorrentes de uma visão negativa do consumidor para com o produto e o fabricante, ou a concessionária que lhe vendeu o automóvel ou prestou o serviço de assistência técnica. Estes dois últimos grupos de categoria também foram importantes na presente análise, pois revelam o modo de atuação da empresa responsável pelo produto. 
Quadro 1: Categorias da motivação de consumo automobilístico brasileiro

\begin{tabular}{|c|c|c|}
\hline Visão & Categoria & Características \\
\hline \multirow{4}{*}{ Positiva } & Hedonista & $\begin{array}{l}\text { satisfação, prazer em dirigir, fortalecimento do ego, apreciação pelo luxo, pela tecnologia } \\
\text { e convergência tecnológica. }\end{array}$ \\
\hline & Devoção & $\begin{array}{l}\text { valorização dos itens de diferenciação, admiração, paixão, identidade positiva, defesa do } \\
\text { produto e/ou do fabricante e sonho de consumo. }\end{array}$ \\
\hline & Valor Social & $\begin{array}{l}\text { extensão da personalidade, status, destaque com relação ao grupo social e afirmação } \\
\text { da personalidade perante o grupo. }\end{array}$ \\
\hline & Utilitarista & $\begin{array}{l}\text { economia, espaço, valor justo, preço atraente, carro para a família, versatilidade, escolha } \\
\text { inteligente, meio de transporte e racionalidade. }\end{array}$ \\
\hline \multirow{2}{*}{ Negativa } & Risco Percebido & $\begin{array}{l}\text { medo, insegurança, desconfiança, fragilidade do fabricante percebida e percepção do } \\
\text { mau posicionamento no mercado do fabricante. }\end{array}$ \\
\hline & Baixo Valor Percebido & $\begin{array}{l}\text { insatisfação, expectativa frustrada, descontentamento com a marca e/ou concessionária } \\
\text { e defasagem entre preço e benefício percebido. }\end{array}$ \\
\hline
\end{tabular}

Fonte: Elaborado pelos autores (2019).

\section{Consumidores hedonistas}

De acordo com Holbrook (1999), o valor para os consumidores que se encontram neste grupo não está tanto no produto adquirido, nem na marca escolhida ou no objeto possuído, mas na experiência que daí deriva. São significados como afeto (prazer versus desprazer), atitude (gostar versus não gostar), avaliação (bom versus ruim), predisposição (favorável versus desfavorável), dentre outros elementos associados à motivação para os consumidores hedonistas.

Todo mundo gosta de viajar. Chegar à praia e sentir a brisa do mar (http://bit.ly/Ah_OMar) ou ir para as montanhas e aproveitar o friozinho é tudo de bom. Mas isso é só o destino final. A viagem até chegar onde você quer é a parte essencial de um bom passeio. E convenhamos: não tem nada melhor do que cair na estrada e sentir a liberdade do asfalto com um carro em que você confia. (p. 23, linhas 53 a 59).

O Jetta é um esportivo disfarçado de sedan por aliar o conforto dos carros premium Volkswagen com a tecnologia dos motores TSI. Faça um test drive e comprove. (p.21, linhas 36 a 38).

Sim 42.000 por um carro 1.0! Cheio de tecnologia, motor potente de 3 cil., câmbio direto, embreagem macia, direção elétrica, alta conectividade com o motorista via Bluetooth, carro nota 10 em segurança... Ford Ka Sedan, mais que recomendo! (p.7, linhas 45 a 51).

A primeira postagem do bloco anterior pertencente ao fabricante Fiat procura mostrar para o público que o ato de dirigir, considerado "friamente", "racionalmente" e "mecanicamente" torna-se mais prazeroso quando está unido à beleza da natureza, à liberdade de andar sobre o asfalto dentro de um carro confiável. Nota-se o esforço do fabricante em induzir o consumidor a dar uma preferência maior aos valores hedônicos em detrimento dos valores utilitários, como seria o de perceber o automóvel como um mero meio de transporte. 
As demais postagens enfatizam o conforto aliado à tecnologia e aos itens de convergência tecnológica percebidos nos diversos serviços integrados, elementos próprios do perfil do consumidor hedonista, uma vez que contribuem para o prazer em dirigir. É descrito claramente que o Bluetooth, a conectividade e as tecnologias em geral fazem dessa proposta, uma experiência que é recomendada pelo consumidor (Li et al., 2017)

Nesse sentido, estão os estudos de autores como Okada (2005), Park (2006) e Lee et al. (2013), os quais ressaltam que os consumidores muitas vezes afirmam pretender comprar um novo produto com base em suas funcionalidades, mas na realidade o que buscam é comprar produtos com características claramente hedônicas, revelando, assim, um desejo de prazer.

\section{Consumidores devotos}

O termo devoção do consumidor implica fervor religioso e inclui elementos de sacralidade. Para o consumidor devoto, os benefícios percebidos por trás de uma marca são de natureza afetiva e não meramente utilitária. Numa sociedade de consumo pós-moderna caracterizada pela secularização da religião e pela sacralização do secular, as marcas de consumo podem assumir aspectos do "sagrado" (Belk, Wallendorf, \& Sherry, 1989).

Ford, tenho um Focus e um Fiesta sedan. Amo Ford, aprendi com meu pai que teve Corcel I e II. Meu sonho é ter um Ford Fusion Branquinho perolado. Entrei numa concessionária e sentei no banco até me vi dirigindo um! (p. 24, linhas 50 a 54).

Tenho um polo 2009 a quatro anos, nunca me deixou na mão. Só manutenção de rotina mesmo...Correias, óleo, pneus. 115.000 km é uma verdadeira máquina. (p. 5, linhas 4 a 6).

O meu é maravilhoso, KA SEL 1.0, amo meu KA, perfeito, lindo!!!! (p.7, linhas 58 a 61).

Eu tenho um Fiat Siena 2010, ele é muito bom, é o carro dos sonhos. No final do ano vou trocar e pegar um desse. Amei. (p. 4, linhas 63 e 64).

A dimensão de devoção manifesta o afeto experiencial associado ao objeto (Batra \& Ahtola, 1990). Pode-se observar em alguns comentários, como os relatados na sequência, uma dinâmica de devoção, de reverência e de paixão observada no comportamento dos consumidores. Para estes, a devoção por trás do automóvel, adquirido ou a ser adquirido, manifesta o sentido e o significado quase que sagrado, justificador da intenção de consumo.

Tenho um 1.4 e gosto muito. Esse é meu primeiro Siena. Amoooooo (p. 5, linhas 4 a 6).

O meu é maravilhoso, KA SEL 1.0, amo meu KA, perfeito, lindo!!!! (p. 7, linhas 58 a 61).

Sonhos de consumo. Essa da cor vinho é irresistível estou trabalhando neste propósito que Deus abençoe. kkkkkkkkkkkkkk (p. 12, linhas 15 a 17).

NÃO preciso de psiquiatra nem de opiniões para escolher alguma coisa, até respeito opiniões educadas de cada um. Sou motorista profissional e conheço carros e já dirigi muitos de outras linhas nacionais, nada tão melhor assim que um VOLKSWAGEN, pelo contrário muitos 
carroças que dizem serem modernas perdem simplesmente em potência e acabamento, é ECONOMIA e falo por conhecimento de viagens. Agora preço, o problema é outro e não do carro, sempre VOLKSWAGEN (p. 13, linhas 38-46).

No terceiro comentário do bloco anterior, observa-se o sonho de consumo como fator motivador para o consumidor potencial do automóvel, o que o está levando a trabalhar para obter o recurso financeiro necessário e, assim, realizar esse seu sonho. Devoção, paixão e sonho de consumo são algumas características presentes no consumidor devoto, características que podem levar o consumidor a justificar o consumo de um bem, no caso desta pesquisa, o automóvel, cujo valor pode ser elevado estando acima das possibilidades financeiras momentâneas de um consumidor, sendo essa mesma limitação relevada frente aos valores decorrentes da devoção que se apresentam no momento de decidir pela compra.

O último comentário apresentado no bloco anterior manifesta a predominância da devoção sobre a questão do preço, sendo essa uma característica também utilitária. Percebe-se nesse comentário a tendência de defesa da marca como decorrência da paixão por parte do consumidor. Defender o produto, a marca ou o fabricante é uma das características da categoria devoção (Arruda-Filho \& Lennon, 2011). Não existe associação dos atributos tecnológicos influenciando esta categoria de usuários, na qual o foco é mantido na marca e no valor sentimental do consumo (Pimentel \& Reynolds, 2004).

\section{Consumidores voltados para o valor social}

Katz e Sugiyama (2006) e Ferreira (2015) atentam para o fato de que o uso de tecnologias possui o caráter modista. Isto pode ser ampliado para a chamada convergência tecnológica presente nos automóveis atuais. Modismo seria quando os usuários adotam produtos por estarem em alta (moda), o que pode proporcionar status mediante outros consumidores. Nesse contexto, o valor social ligado à moda, status e diferenciação, leva ao consumo e não a uma finalidade utilitária, mas sim a uma relação de poder, integração, inserção e distinção para o usuário.

Conheço gente que nem anda de carro, mas troca a cada dois anos só pra deixar ele na garagem para os vizinhos verem. (p. 11, linhas 1 a 8).

Focus onde você sempre quis: na sua garagem. Você está perto de dirigir o seu. (p. 19, linhas 59 a 62).

... mas brasileiro vive de aparência... (p. 30, linha 61).

São comentários que procuram estimular o consumo através de uma motivação pelo status, ou no qual se percebe a motivação pela inserção no grupo social ou pelo destaque dentro do grupo. São, portanto, motivações associadas ao valor social visando o exibicionismo, status social e posicionamento no grupo (Katz \& Sugiyama, 2006).

Já os comentários apresentados na sequência manifestam que, por trás do consumo, se encontra a busca pela extensão do "self", da própria personalidade (Belk, 1988). 


\begin{abstract}
A Ford acredita que lugar de mulher é na direção. Afinal, estar na direção é ter a liberdade de escolher o que você quiser, onde você quiser. ( $p$. 24, linhas 46 a 49).

Concordo em ter a direção de um Ford para saber onde é meu lugar. (p. 24, linhas 59 a 61).
\end{abstract}

Meu Neto chama de "caminhãozinho do vovô. É o carro da família que ele mais gosta de "andar". (p. 28, linhas 1 a 4).

Raça forte. Só fazer a manutenção e "socar a bota". Caminhonete show em tecnologia, estabilidade e conforto. (p. 25, linhas 54 a 60).

O FIAT Club é um clube de vantagens e benefícios que qualquer um pode participar, mesmo quem ainda não tem um Fiat. Passe o gif e descubra tudo o que você pode aproveitar para viver a vida de um jeito mais Fiat. (p. 1, linhas 4 a 7).

O valor social está ligado ao status e ao posicionamento que o uso da tecnologia proporciona para o usuário, tecnologia esta que pode representar o apelo determinante no consumo de um modelo de automóvel. Belk (2013) e Ferreira (2015) ressaltam que, na rede online, os usuários tendem a estender suas personalidades, gostos, opiniões e críticas. Essa atitude fortalece ainda mais a intenção de consumir um determinado modelo ou marca de automóvel, para assim sentir-se pertencente a um grupo social e ser um entre os seus iguais.

Apenas um comentário apresenta descrição sobre a tecnologia como influência nos valores sociais do produto, a qual não é detalhada, mas citada de forma geral, demonstrando uma percepção de valor adicional, mas nada de grande afeto e efeito no indivíduo.

\title{
Consumidores utilitaristas
}

O consumo motivado por valores utilitários se caracteriza por razões de finalidade, funcionalidade, atributos não sensoriais e também por deliberações mais racionais que emotivas (Holbrook \& Hirschman, 1982; Millar \& Tesser, 1986; Triandis, 1977; Khan, Dhar, \& Wertenbroch, 2004) ; Khan \& Dhar, 2010). Usuários deste perfil estão em busca, normalmente, de características funcionais e práticas que lhe tragam benefícios mais tangíveis, como melhor custo versus benefício, dentre outros.

carro excelente, performance e economia, seguro barato, melhor custo benefício na categoria de carros acima dos 100.000,00, é difícil ver um carro tão forte (p. 32, linhas 36 a 39).

No comentário apresentado na sequência, percebe-se também 0 esforço do fornecedor no sentido de unir atributos utilitários como espaço, oferta e forma de pagamento facilitada com tecnologia e potência, atributos hedônicos, para tornar a compra do automóvel mais atraente.

$\mathrm{Na}$ Ford você encontra exatamente o carro que procura. Tem pacote com potência, espaço, tecnologia ou com Taxa Zero em 24x. Qual será o seu? (p.7, linhas 29 a 31).

O prazer de dirigir e uma oferta que cabe no seu bolso. (p. 19, linha 56).

Há, no entanto, consumidores mais influenciados pelos valores utilitários e preocupados excessivamente com a questão de um custo mais baixo (que caiba no seu bolso). Em situações como essa, pode-se observar, como 
no segundo comentário mencionado anteriormente e feito pela Ford, seu esforço em reforçar o valor hedônico do prazer de dirigir, unindo-o a um motivo utilitário, a oferta, para estimular a decisão pelo consumo. Essa atitude do fabricante corrobora uma tendência ressaltada por Okada (2005) e Ozcan e Sheinin (2015), de que o consumidor procura minimizar seu sentimento de culpa, apoiando-se em atributos utilitários do produto, quando na realidade sua decisão de compra foi motivada por atributos hedônicos.

\section{Risco percebido}

Alguns comentários coletados nesta pesquisa refletem a percepção do risco diante da possibilidade de compra de um determinado modelo de automóvel ou diante de uma determinada marca. Essa percepção é manifestada por termos como "medo" e "preocupação" ou diante de comentários negativos de outros consumidores insatisfeitos, bem como alertas no sentido de tomar cuidado com determinado fabricante.

Risco é uma função das incertezas e suas possíveis consequências (Engel, Blackwell, \& Miniard, 1995; Stem, Lamb, \& Maclachlan, 1977). O ato da compra supõe assumir um risco e cabe ao consumidor, de alguma forma, reduzir esse risco, uma vez que as duas dimensões envolvidas no risco, incerteza e consequência, afetam o comportamento de compra (Bauer, 1960; Cunningham, 1967; Zikmund \& Scott, 1974).

\footnotetext{
Muitos comentários que o carro não presta (p. 11, linha 19).

Medo, acabei de comprar meu Titanium AWD e lendo os comentários de vocês fiquei preocupado. O carro é top, não vejo outro melhor nesse valor, mas essa história das peças.... (p.16, linhas 36 a 39).

Só tem que tomar cuidado pq se tiver recall você fica 30 dias sem o carro. Vocês não respeitam o consumidor! Nem Uber Fiat pego mais. (p. 17, linhas 28 a 31).
}

Os comentários de caráter negativo presentes nas redes sociais, ao demonstrarem a percepção de risco por parte dos consumidores, são um fator de disseminação da experiência negativa com um produto ou uma marca. Kozinets (2002) ressalta que, para alguns consumidores que possuem laços fortes em função de seu relacionamento no grupo online, a comunicação nesse grupo é profundamente detalhada dos indivíduos, em função de suas posições, preferências e opiniões.

Desta forma, comentários que manifestam insegurança perante uma decisão de consumo representam para os fabricantes informações muito importantes, à medida que através desse tipo de comentário sua reputação ou a qualidade dos seus produtos ficam comprometidas. Esses comentários postados no próprio Facebook dos fabricantes se transformam num instrumento valioso de relacionamento com os consumidores, exigindo, entretanto, das empresas uma forma ágil e adequada para diminuir a percepção de risco de seus consumidores.

As percepções de risco podem não ser um problema, desde que os consumidores focalizem sua necessidade em múltiplas funções e características do produto em questão (Gjerde, Slotnick, \& Sobel, 2002; Harris \& Blair, 2006; Snoj, Korda, \& Mumel, 2004). Cabe, portanto, aos fabricantes 
saberem explorar adequadamente os atributos hedônicos, sociais e utilitários dos seus produtos no sentido de minimizar a percepção de risco nos seus consumidores.

\section{Baixo valor percebido}

Outra categoria associada à imagem negativa de uma marca e/ou do fabricante é o baixo valor percebido. Esta exige uma reação do fabricante análoga ao risco percebido, sendo a diferença entre essas duas categorias a de que, no risco percebido, o consumidor se encontra no momento de decidir pela compra e está procurando informações que the reduzam o desconhecimento do produto, já que o desconhecimento gera a percepção de risco. No caso do baixo valor percebido, a insatisfação do consumidor decorre de uma expectativa frustrada diante de uma compra já realizada.

Para Schechter (1984) e Zeithaml (1988, p. 13), valor, para o cliente, são todos os fatores, qualitativos e quantitativos, subjetivos e objetivos, que compõem a experiência completa de compra; e valor percebido é a avaliação geral feita pelo consumidor quanto à utilidade de um produto baseado em percepções do que é recebido e do que é dado (Zeithaml, 1988, p. 14). Costa (2007) enfatiza que a discrepância entre o valor esperado pelo consumidor e o valor recebido diante de um produto e, consequentemente, diante de uma marca, leva o cliente à atitude natural de reclamação, expressão da sua insatisfação.

consumo absurdo. Nunca vi nada igual. Fui uns dos primeiros a ter $e$ vendi com 40 dias depois. Não recomendo. (p. 11, linhas 55 a 57).

\#velotrol [um velocípede de criança]. (p. 13, linha 25).

Carroça ambulante (p. 13, linha 27)

Comprei um Freestyle 2.0 powershift $0 \mathrm{~km}$ e fiquei por quase dois anos. 3 anos de decepção e raiva e vários dias (pelo menos 6 meses contando todas as idas para a oficina) com carro reserva porque não descobriam os inúmeros defeitos que o carro apresentava (...). Em resumo uma alegria quando comprei e uma outra maior ainda quando vendi. Faltou respeito pela concessionária e a marca Ford em me devolver o dinheiro investido. Ford e sua concessionária Ford Dimas, nunca mais. (p. 14, linhas 44 a 56).

Estes comentários demonstram, de maneira irônica e sarcástica, a insatisfação com relação ao consumo ora com o produto, ora com o fabricante. A insatisfação ocasionada por uma expectativa frustrada leva o consumidor que passou por essa experiência negativa a não recomendar o produto adquirido.

Trata-se de apenas alguns comentários negativos, selecionados dentre vários presentes no Facebook das três montadoras. Entretanto, a observação da ocorrência num volume considerável desse tipo de comentário leva à percepção da importância dos fabricantes estarem atentos a essas ocorrências, uma vez que representam uma fonte significativa de informações, por revelarem de forma objetiva e sincera os sentimentos dos consumidores.

Na coleta das discussões detectaram-se alguns retornos das montadoras, sendo na maioria das vezes um posicionamento de que a situação específica 
daquele consumidor estava em andamento, e que se solicitava aguardar a solução ou, em outras vezes, a montadora solicitava que o consumidor se dirigisse a ela por outro canal de comunicação de caráter privado.

Sinais informacionais e ambientais são elementos importantes para compreender o comportamento do consumidor, auxiliando as empresas na sua capacidade de predizer a forma deste agente reagir (Schiffman \& Kanuk, 2000, p. 6). Assim, percebe-se a importância da utilização das redes sociais como um canal de relacionamento com os consumidores para entender o comportamento destes, o que os leva a preferir tal ou qual modelo e gerenciar as suas expectativas, bem como suas insatisfações.

\section{Considerações Finais}

A apresentação das análises realizadas neste estudo, referente às características de motivação do consumo automobilístico brasileiro por meio do uso de uma ferramenta de Big Data, deve ser iniciada pelo problema que o motivou, que é o de procurar entender se a convergência tecnológica influenciou na percepção de valor dos consumidores (valores emocionais e racionais), de forma a levar à intenção de consumo desses usuários do mercado automobilístico brasileiro.

De maneira mais específica, a presente pesquisa objetivou, por um lado, descrever como a percepção de novas tecnologias integradas aos automóveis modificou a percepção de valores hedônicos, utilitários e sociais, influenciando a intenção de consumo dos automóveis e, por outro, tratou-se de identificar qual desses três valores exerceu maior influência na intenção de consumo de automóveis no mercado brasileiro.

Foram encontradas seis categorias que representam os fatores motivacionais de consumo do produto automóvel. Pela análise feita por meio dos comentários coletados e selecionados como os mais representativos, a primeira constatação a que se chega é, por um lado, a confirmação da existência dos três tipos de valores: os hedônicos, os utilitários e os sociais, os quais influenciam o consumo. A existência desses três valores se organiza como fator motivacional de consumo por meio das suas próprias características tais como prazer em dirigir e apreciação pela tecnologia, quanto aos valores hedônicos, economia e racionalidade na decisão de compra, no caso dos valores utilitários e extensão da personalidade e afirmação desta perante o grupo social com relação aos valores sociais, dentre outras características.

Apenas os valores emocionais de hedonismo e o valor social tiveram influência da percepção da tecnologia convergida nos automóveis discutidos, no qual os outros valores foram focados na marca e experiência de mobilidade com este. Uma quarta categoria motivacional também constatada no levantamento realizado: a devoção para com o produto e/ou fabricante. Características como sonho de consumo, paixão e defesa do produto e/ou fabricante, próprias dessa categoria, se manifestaram com uma frequência expressiva no período pesquisado. 
O termo "irresistível" contido num dos comentários hedônicos mencionados e outros semelhantes foram observados também em vários outros comentários coletados, porém não apresentados no capítulo da análise dos dados. Esse termo manifesta que é tal a intenção de consumo frente às características hedônicas do automóvel, que o consumidor está disposto a superar, por exemplo, a dificuldade do preço elevado, uma característica utilitária, para consumar sua decisão de compra. Essa constatação vem a corroborar o que alguns autores como Okada (2005), Holbrook (1999) e Heath e Soll (1996) mencionam a respeito da justificação do consumo quando este tem por base a motivação hedônica prevalecendo sobre a motivação utilitária.

A terceira constatação se refere ao contexto da presente pesquisa que é o da convergência tecnológica. Em alguns comentários coletados, os consumidores ou os fabricantes fazem referência ao apelo tecnológico do carro em questão. Este apelo de caráter hedônico manifesta, no caso do consumidor, um elemento justificador do consumo ou de atração para um modelo específico de automóvel. No caso do fabricante, percebe-se o esforço por motivar o consumo de seus produtos a partir das características de convergência tecnológica, representada na maior parte das vezes por um sistema que reúne as diversas funcionalidades tais como conexão com o sistema de som, GPS, câmara de ré, dentre outras; ou de alguns diferenciais tecnológicos relacionados à potência do motor, desempenho, câmbio (automático ou semiautomático) e outros recursos. Essa atitude comum aos fabricantes e aos consumidores permite afirmar que o automóvel é visto atualmente como um produto "tecnológico", dado que suas características tecnológicas vêm exercendo também um papel importante na intenção de consumo.

Vale ressaltar, no entanto, que a percepção por parte dos consumidores está sendo maior com relação aos aspectos tecnológicos do automóvel de maneira geral do que com a convergência tecnológica digital, pois foram poucos os comentários explicitando a percepção desse último elemento. Nota-se, sim, um esforço por parte dos fabricantes em fortalecer a percepção da convergência tecnológica nos participantes da comunidade online pesquisada, visto a significativa ocorrência de suas postagens, especialmente através de propagandas, por meio das quais os fabricantes reforçaram essa convergência presente nos automóveis por eles fabricados. Entretanto, as discussões nos sites perdem o foco do atributo tecnológico proposto no tema da discussão e foca-se na identidade do automóvel e sua marca em si.

Neste estudo objetivou-se também compreender, dentre os valores hedônicos, utilitários e sociais, qual é aquele que exerce maior participação na intenção de consumo de automóveis no mercado brasileiro. Pelo critério de quantidade dos comentários, observou-se uma prevalência das categorias hedonista e de devoção com relação às outras duas, utilitária e valores sociais. Compreende-se que a incidência de comentários da categoria de devoção acompanha a expressividade de ocorrência de comentários de cunho hedonista, uma vez que a primeira representa uma resposta positiva aos apelos feitos pelos fabricantes, ressaltando os valores hedônicos dos seus produtos. 
Constatou-se também a ocorrência de comentários relacionados a outras duas categorias, sendo estas: "Risco Percebido" e "Baixo Valor Percebido". Na primeira categoria há a manifestação de uma desconfiança e um temor diante da possibilidade de consumir um automóvel que possa trazer ao consumidor um problema futuro. Na percepção de baixo valor com o produto, a compra já ocorreu e o consumidor está insatisfeito, principalmente porque a expectativa em função dos benefícios não se efetivou, uma vez que os benefícios não foram percebidos, além de que muitas vezes sua experiência negativa de compra foi agravada pelo mau atendimento diante de problemas de ordem técnica, como defeito de funcionamento de algum componente.

É importante mencionar essas duas categorias na análise dos dados e nas conclusões, devido à quantidade significativa de ocorrências de comentários com esse teor, especialmente da categoria "baixo valor percebido". Conclui-se, assim, que esses comentários vindos dos consumidores desconfiados, temerosos e insatisfeitos representam informações preciosas para os fabricantes. Cabe a estes saberem utilizá-las de forma oportuna e adequada para gerenciar insatisfações e frustrações dos consumidores atuais e potenciais, transformando isso em resultados positivos para a empresa.

Por fim, foi observado na presente pesquisa a forte utilização do Facebook como meio de veiculação dos anúncios por parte dos três fabricantes, manifestando, assim, como essa rede social se tornou um importante canal não só de comunicação, caracterizado pelas interações em forma de resposta a alguns comentários por parte dos consumidores satisfeitos ou insatisfeitos, mas também como canal de promoção e propaganda dos seus produtos, por mais que outras redes mais atuais como Instagram e Twitter também tenham mais recentemente apresentado muitas contribuições nesta temática.

\section{Limitações da pesquisa}

Uma limitação a ser mencionada se refere à metodologia. Devido à dificuldade de acesso, não se realizou entrevistas com os consumidores, um procedimento recomendado para se aprimorar a qualidade das informações obtidas. Embora essa limitação não comprometa os resultados encontrados, certamente enriqueceria os mesmos.

Outra limitação está relacionada à aplicação da ferramenta para coleta dos dados. Como já mencionado, foi utilizada neste estudo uma ferramenta baseada no Big Data que auxiliou a coleta, tornando-a mais rápida. No entanto, essa ferramenta apresentou alguns desajustes quanto à classificação dos comentários nas categorias positiva, negativa e neutra. Percebeu-se que alguns comentários nitidamente de caráter positivo foram classificados como negativos e vice-versa. Esses equívocos são compreensíveis, uma vez que vários comentários contêm termos irônicos, impossíveis de serem interpretados adequadamente por um software. Assim, diante dessa limitação, surgiu a necessidade de que essa interpretação fosse feita pelo próprio pesquisador. 
Também se obteve como limitação a análise apenas da rede social Facebook, podendo ser expandido para o Instagram e Twitter, que entretanto pelo número de postagens, a análise necessitaria de ajuda via software do tipo Nvivo ou Atlas-ti.

O objetivo central do estudo não foi completamente atendido, pois existe alguma percepção da convergência tecnológica nos automóveis influenciando os valores sociais e hedônicos de consumo, mas as outras categorias em nada são afetadas pela percepção de atributos tecnológicos em um mesmo produto, neste caso, o automóvel. Acredita-se, assim, que os sistemas de multimídia e tecnologia digital integradas nos carros, no período de pesquisa em questão, foram percebidos apenas como valores adicionais para aqueles consumidores que buscam mais fatores emocionais que racionais de consumo, mas que estes atributos convergentes não são especificamente responsáveis por uma maior motivação de consumo.

\section{Recomendações para pesquisas futuras}

A presente pesquisa se restringiu ao estudo da influência da convergência da tecnologia nas características de motivação do consumo de automóveis no mercado nacional e, como resultado do levantamento de dados realizado, obteve-se não só informações diretamente ligadas aos valores hedônicos, utilitários e sociais, escopo da pesquisa, mas obtiveram-se também informações dos fatores que geram a insatisfação no consumidor, que foram o risco percebido e o baixo valor percebido, que não estiveram relacionados às tecnologias integradas em si. Desta forma, caberiam futuras pesquisas voltadas para uma análise mais profunda desses fatores negativos em termos motivacionais. Como já descrito, a análise desses fatores, além de contribuir para a Academia, contribui também para a área gerencial por representar uma fonte de apoio na gestão dos consumidores por parte das empresas.

\section{Agradecimentos}

Este artigo foi baseado na dissertação de mestrado de Luis Augusto Molina Alexandroni. Emílio Arruda Filho foi o orientador de mestrado de Luíz Alexandroni, o qual trabalhou no planejamento do projeto de pesquisa para desenvolver um manuscrito robusto com base no estudo, que foi analisado e discutido entre os autores ao longo de todo o processo de revisão (três rodadas). Gostaríamos de agradecer ao editor Luciano Rossoni, por supervisionar o processo e por seu importante feedback sobre a pesquisa, bem como os três revisores por seus valiosos comentários, sugestões e considerações que garantiram um melhor manuscrito final. Nós também gostaríamos de agradecer à Universidade da Amazônia e à Universidade FUMEC pelo apoio ao longo da pesquisa, e expressar nossa gratidão pelo apoio financeiro recebido do Governo Brasileiro por meio das instituições CAPES, CNPq e FAPEMIG. Por fim, agradecemos a empresa E.Life por conceder a utilização do software Buzzmonitor na sua versão Freemium durante a coleta e análise dos dados. 


\section{Referências}

Associação Nacional dos Fabricantes de Veículos Automotores (2016). Anuário da Indústria Automobilística Brasileira. Recuperado em 26 julho, 2016, de http://www. anfavea.com.br/anuario.html.

Associação Nacional dos Fabricantes de Veículos Automotores. (2020). Anuário da Indústria Automobilística Brasileira. Recuperado em 19 maio, 2020, de http://www. anfavea.com.br/anuarios.

Arruda Filho, E. J. M. (2020). Análise da Pesquisa Netnográfica: exemplos ilustrativos no campo da administração. In J. Brunstein, A. S. Godoy, E. P. Z. Brito \& E. J. M. Arruda Filho (Orgs.). Análise de dados qualitativos em pesquisa: múltiplos usos em administração (pp.604-622). São Paulo: FGV Editora e Mackenzie Editora.

Arruda-Filho, E. J. M., \& Dholakia, R. R. (2013). Hedonismo como um fator de decisão e uso tecnológico. Revista Brasileira de Gestão de Negócios, 15(48), 343-361.

Arruda-Filho, E. J. M., \& Lennon, M. M. (2011). How iPhone innovators changed their consumption in iDay2: hedonic post or brand devotion. International Journal of Information Management,31 (6), 524-532 Doi:10.1016/j.jijnfomgt.2011.04.007.

Alsharif, N., \& Shen, X. (2014). IEEE ICC 2014 - Mobile and Wireless Networking Symposium. Sydney, NSW, Australia.

Bardin, L. (1979). Análise de conteúdo (L. A. Reto \& A. Pinheiro, Trads.). Lisboa: Edições 70.

Batra, R., \& Ahtola, O. T. (1990). Measuring the hedonic and utilitarian sources of consumer attitudes. Marketing Letters, 2(2), 159-170.

Bauer, R. (1960). Consumer behavior as risk taking. In R. Hancock (Ed.). Dynamic marketing for a changing world. Chicago: American Marketing Association, 389-398.

Beleza, A. (2013). Buzzmonitor mede a performance e retorno do investimento nas Redes Sociais. Recuperado em 24 setembro, 2020, de https://www.techenet. com/2013/02/buzzmonitor-mede-a-performance-e-retorno-do-investimento-nasredes-sociais/.

Belk, R. W. (1988, September). Possessions and the extended self. Journal of Consumer Research, 15.

Belk, R., \& Kozinets, R. (2017). Videography and netnography. In K. Kubacki \& S. Rundle-Thiele (Eds.). Formative research in social marketing: innovative methods to gain consumer insights (pp.265-279). Singapore: Springer.

Belk, R. W., Wallendorf, F, M., \& Sherry, J. (1989, June). The sacred and the profane in consumer behavior: theodicy on the odyssey. Journal of Consumer Research, 15, 1-38.

Belk, R. W. (2013). Extended self in a digital world. Journal of Consumer Research, 4O(3), 477-500.

Blackwell, R. D., Miniard, P. W., \& Engel, J. F. (2008). Comportamento do consumidor (9a ed.). São Paulo: Cengage Learning.

Campbell, C. (1987). The romantic ethic and the spirit of modern consumerism. Oxford: Blackwell Publishers. 
Cunningham, S. M. (1967). The major dimensions of perceived risk. In D. F. Cox (Ed.). Risk taking and information handing in consumer behavior (pp. 82-108). Boston: Harvard University Press.

Costa, F. J. (2007, no prelo). A influência do valor percebido pelo cliente sobre os comportamentos de reclamação e boca a boca: uma investigação em cursos de pós-graduação lato sensu. Tese de Doutorado, Escola de Administração de Empresas de São Paulo, São Paulo, SP, Brasil.

Dhar, R., \& Wertenbroch, K. (2000). Consumer choice between hedonic and utilitarian goods. Journal of Marketing Research, 37, 60-71.

Douglas, M; Isherwood, B. (1978). The world of goods. Middlesex: Penguin.

Durkheim, É. (1968). Representações individuais e representações coletivas In: É. Durkheim. Sociologia e filosofia (pp.15-49). Rio de Janeiro: Forense.

Engel, J. F., Blackwell, R. D., \& Miniard, P. W. (1995). Consumer Behavior (8a ed.). Orlando: The Dryden Press.

Ferreira, N. S. (2015, no prelo). Preferência de uso dos aplicativos de redes sociais nos dispositivos móveis: uma análise da usabilidade tecnológica. Dissertação de Mestrado, Universidade da Amazônia, Belém, PA, Brasil.

Frese, T., Gerber, N., Hatebur, D., Côté, I., \& Heisel, M. (2018). Functional safety processes and advanced driver assistance systems: evolution or revolution? In H. Proff \& T. M. Fojcik (Eds.). Mobilität und digitale Transformation (pp. 199-216). Wiesbaden: Springer Gabler.

Furlan, R. (2015). Fiat anuncia central multimídia para Linea e Punto: dispositivo é a grande novidade da linha 2016 dos modelos. Quatro Rodas. Recuperado em 30 março, 2017, de http://www.quatrorodas.abril.com.br/noticias/fiat-anuncia-centralmultimidia-para-linea-epunto/.

Gjerde, K. A., Slotnick, S. A., \& Sobel, M. J. (2002). New product innovation with multiple features and technology constraints. Management Science, 48(10), 1268-1284.

Goldenberg, J. L. B., \& Muller, E. (2001). Talk of the network: a complex system look at the underlying process of word-of-mouth. Marketing Letters, 12(3), 211-223.

Günther, H. (2006, maio-agosto). Pesquisa qualitativa versus pesquisa qualitativa esta é a questão? Psicologia: Teoria e Pesquisa, 22(2), 201-210.

Harris, J., \& Blair, E. A. (2006). Functional compatibility risk and consumer preference for product bundles. Journal of the Academy of Marketing Science, 34(1), 19-26.

Heath, C., \& Soll, J. B. (1996, June). Mental budgeting and consumer decisions. Journal of Consumer Research, 23(1), 40-52.

Hirschman, E. C., \& Holbrook, M. B. (1982, July). Hedonic consumption: emerging concepts, methods, and propositions. Journal of Marketing, 46, 92-101.

Hofacker, C. F., Malthouse, E. C., \& Sultan, F. (2016, February). Big data and consumer behavior: Imminent opportunities. Journal of Consumer Marketing, 33(2), 89-97.

Holbrook, M. B. (1999). Consumer value: a framework for analysis and research. New York: Routledge.

Katz, J. E., \& Sugiyama, S. (2006). Mobile phones as fashion statements: evidence from student surveys in the US and Japan. New Media \& Society, 8(2), 321-337. 
Khan, U., Dhar, R., \& Wertenbroch, K. (2004). A behavioral decision theoretic perspective on hedonic and utilitarian choice. In S. Ratneshwar \& D. G. Mick (Eds.). Inside consumption: frontiers of research on consumer motives, goals, and desires (pp. 144-165). New York: Routledge.

Khan, U., \& Dhar, R. (2010). Price-framing effects on the purchase of hedonic and utilitarian bundles. Journal of Marketing Research, 47(6), 1090-1099.

Kim, Y., Lee, J. D., \& Koh, D. (2005). Effects of consumer preferences on the convergence of mobile telecommunications devices. Applied Economics, 37(7), 817-826.

Kimura, H., Basso, L. F. C., \& Martin, D. M. L. (2008). Redes sociais e o marketing de inovações. RAM - Revista de Administração Mackenzie, 9(1), 157-181.

Kozinets, R. V. (1999). E-Tribalized marketing? The strategic implications of virtual communities of consumption. European Management Journal, 17(3), 252-264.

Kozinets, R. V. (2002, February). The field behind the screen: using netnography for marketing research in online communities. Journal of Marketing Research, 39, 61-72.

Kozinets, R. V. (2014). Netnografia: realizando pesquisa etnográfica online, Porto Alegre: Penso.

Kozinets, R. V., Scaraboto, D., \& Parmentier, M. A. (2018). Evolving netnography: how brand auto-netnography, netnographic sensibility, and more-than-human netnography can transform your research. Journal of Marketing Management, 34(3-4), 231-242.

Langer, R., \& Beckman, S. C. (2005). Sensitive research topics: Netnography revisited. Qualitative Market Research: An International Journal, 8(2), 189-203. https:// doi. org/10.1108/13522750510592454.

Lee, S., Lee, J. H., \& Garrett, T. C. (2013). A study of the attitude toward convergent products: A focus on the consumer perception of functionalities. Journal of Product Innovation Management, 30(1), 123-135.

Li, E. L. Y., Liu, B. S. C., \& Luk, S. T. K. (2017). Customer participation behavior in high- versus low-contact services: The multiple roles of customer trust. Journal of Global Marketing, 30(5), 322-341. https://doi.org/10.1080/08911762.2017. 1343886

Maniyka, J., Chui, M., Brown, B., Bughin, J., Dobbs, R., Roxburgh, C., \& Byers, A. H. (2011, May). Big data: the next frontier for innovation, competition, and productivity. McKinsey Global Institute. Recuperado em 10 setembro, 2015, de http://www. mckinsey.com/insights/mgi/research/technology_and_innovation/big_data_the_ next_frontier_for_innovation.

Mano, H., \& Oliver, R. L. (1993, December). Assessing the dimensionality and structure of the consumption experience: evaluation, feeling, and satisfaction. Journal of Consumer Research, 20, 451-466.

Mauss, M. (1974). Ensaio sobre a dádiva: forma e razão da troca nas sociedades arcaicas. In: M. Mauss. Sociologia e antropologia (pp. 37-184). São Paulo: EPU.

Mayer-Schönberger, V., \& Cukier, K. (2013). Big Data como extrair volume, variedade, velocidade e valor da avalanche de informação cotidiana, Rio de Janeiro: Elsevier.

Mayfield, A. (2008). What is social media? iCrossing. Recuperado em 1 janeiro, 2015, de http://www.repromax.com/docs/113/854427515.pdf. 
Medeiros Neto, B. (2016, julho-dezembro). As contribuições de projetos colaborativos de ubiquidade, convergência, hibridismo na mobilidade informacional de um território. Revista Ibero-Americana de Ciência da Informação, 2(9), 365-386.

Meyer, R. J., \& Sathi, A. (1985, February). A multiattribute model of consumer choice during product learning. Marketing Science, 4(1), 41-61.

Millar, M. G., \& Tesser, A. (1986). Effects of affective and cognitive focus on the atitudebehavior relationship. Journal of Personality and Social Psychology, 51, 270-276.

Ministério do Desenvolvimento, Indústria e Comércio Exterior. Brasil + Produtivo: Automotivo. (2016, janeiro). Portal Institucional. Recuperado em 28 julho, 2016, de http://www.mdic.gov.br/index.php/competitividade-industrial/principais-acoes-dedesenvolvimento-industrial/brasil-produtivo

Mowen, J. C., \& Minor, M. S. (2002). Comportamento do consumidor. São Paulo: Prentice Hall.

Muniz Jr., A. M, \& O'Guinn, T. C. (2001, March). Brand community. Journal of Consumer Research, 27, 412-432.

Nayeem, T., \& Casidy, R. (2015). Australian consumers' decision-making styles for everyday products. Australasian Marketing Journal, 23(1), 67-74.

Okada, E. M. (2005, February). Justification effects on consumer choice of hedonic and utilitarian goods. Journal of Marketing Research, 42(1), 43-53.

Ozcan, T., \& Sheinin, D. (2015). The effects of changing attribute composition on judgments about multifunctional products. Journal of Marketing Theory and Practice, 23(1), 107-118.

Papista, E., Chrysochou, P., Krystallis, A., \& Dimitriadis, S. (2018). Types of value and cost in consumer-green brands relationship and loyalty behaviour. Journal of Consumer Behaviour, 17, e101-e113.

Park, C. (2006). Hedonic and utilitarian values of mobile internet in Korea. International Journal of Mobile Communications, 4(5), 497-508.

Pereira, J. P. N. (2016). Determinantes da intenção de compra de marcas de automóveis de passageiros. Tese de Dissertação de Mestrado, Instituto Politécnico de Leiria, Leiria, Portugal.

Perrea, T., Grunert, K. G., \& Krystallis, A. (2015). Consumer value perceptions of food products from emerging processing technologies: a cross-cultural exploration. Food Quality and Preference, 39, 95-108.

Petrock, V. (2020). The era of intelligent connectivity draws closer. Top 10 Techs Trends for 2020. Recuperado em 24 setembro, 2020, de https://www.emarketer. com/content/top-10-tech-trends-for-2020.

Pimentel, R. W., \& Reynolds, K. E. (2004). A Model for consumer devotion: affective commitment with proactive sustaining behaviors. Academy of Marketing Science Review, 2004(5). Recuperado em 15 março, 2017, de http:// www.expected.com/ white_paper/A_model_for_consumer_expect_advertising_inc.pdf.

Prado, J. M. K., Lucas, E. R. O., \& Herrero-Curiel, E. (2013). As bibliotecas nacionais iberoamericanas na web 2.0: resultados parciais sobre o Facebook. XXV Congresso Brasileiro de Biblioteconomia, Documentação e Ciência da Informação, Florianópolis, FEBAB/ACB,25. 
Rocha, E., \& Barros, C. (2006, outubro-dezembro). Dimensões culturais do marketing: teoria antropológica, etnografia e comportamento do consumidor. RAE, 46(4), 1-12.

Sahin, A. Z., Zehir, C., \& Kitapçi, H. (2011). The effects of brand experiences, trust and satisfaction on building brand loyalty: an empirical research on global mobile phone brands. Procedia Social and Behavioral, 24, 1288-1301.

Sahlins, M. (1979). Cultura e razão prática. Rio de Janeiro: Zahar.

Satish, S. M., Bharadhwaj, S. (2010). Information search behavior among new car buyers: two-step cluster analysis. IIMB Management Review, 22, 5-15.

Schechter, L. (1984). A normative conception of value. Progressive Grocer. Executive Report (pp.12-14).

Schiffman, L. G., \& Kanuk, L. L. (2000). Comportamento do consumidor. Rio de Janeiro: LTC.

Sela, A., \& Berger, J. (2012, December). How attribute quantity influences option choice. Journal of Marketing Research, 49, 942-953.

Shamdasani, P. N., Stanaland, A. J., \& Tan, J. (2001, July). Location, location, location: insights for advertising placement on the web. Journal of Advertising Research, 41, 7-21.

Sharma, R.; Ahuja, V., \& Alavi, S. (2018). The future scope of Netnography and social network analysis in the field of marketing. Journal of Internet Commerce, 17(1), 2645.

Sheth, J. N., Mittal, B., \& Newman, B. (2001). Comportamento do cliente: indo além do comportamento do consumidor. São Paulo: Atlas.

Smith, R., \& Smith, L. (2018). Qualitative methods. In L. Mcconnell \& R. Smith (Eds.). Research Methods in Human Rights (pp. 78-101). New York, Routledge.

Snoj, B., Korda, A. P., \& Mumel, D. (2004). The relationships among perceived quality, perceived risk and perceived product value. The Journal of Product and Brand Management, 13(3), 156-167.

Stem, D. E. Jr., Lamb, C. W. Jr., \& Maclachlan, D. L. (1977). Perceived risk: a synthesis. European Journal of Marketing, 11(4), 312-319.

Strahilevitz, M. A., \& Myers, J. G. (1998, March). Donations to charity as purchase incentives: how well they work may depend on what you are trying to sell. Journal of Consumer Research, 24, 434-446.

Toledo, V. (2020). Três serviços já disponíveis que prometem deixar seu carro inteligente. Techtudo. Recuperado em 21 setembro, 2020, de https: //www. techtudo.com.br/listas/2020/08/tres-servicos-ja-disponiveis-que-prometem-deixarseu-carro-inteligente.ghtml.

Triandis, H. C. (1977). Interpersonal behavior. Monterey: Brooks/ Cole Publishing Co..

Veludo-de-Oliveira, T. M., \& Ikeda, A. A. (2005, janeiro-abril). O conceito de valor para o cliente: definições e implicações gerenciais em marketing. Revista Eletrônica de Gestão Organizacional, 3(1), 39-52.

Woodruff, R. B. (1997, Spring). Customer value: the next source of competitive advantage. Journal of Academy of Marketing Science, 25(2), 139-153. 
Revista Eletrônica de Ciência Administrativa

Yoon, S. B., \& Cho, E. (2016). Convergence adoption model (CAM) in the context of a smart car service. Computers in Human Behavior, 60, 500-507.

Zeithaml, V. A. (1988, July). Consumer perceptions of price, quality, and value: a means-end model and synthesis of evidence. Journal of Marketing, 52, 2-22.

Zikmund, W. G., \& Scott, J. E. (1974). Variety analysis of perceived risk self-confidence and information sources. Advances in Consumer Research, 1, 406-416.

Notas

i Buzzmonitor - solução desenvolvida e comercializada pelo grupo empresarial E.life.

ii Empresa norte-americana que gerencia fontes de informação e fornece dados para pesquisa de mercado, dentre outras áreas. 